\title{
Former CSSI President Tangchun Wu elected to the Chinese Academy of Engineering
}

\author{
Robert M. Tanguay ${ }^{1} \cdot$ Lawrence E. Hightower $^{2}$
}

Accepted: 15 December 2021 / Published online: 5 January 2022

(c) The Author(s) under exclusive licence to Cell Stress Society International 2021

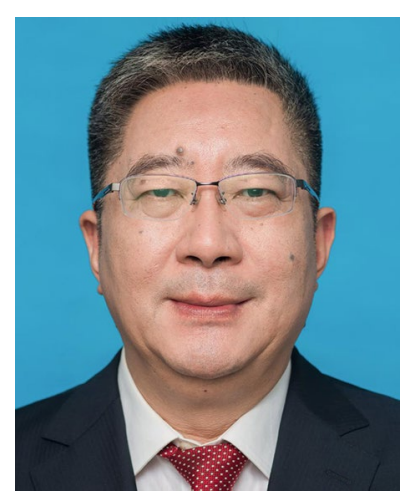

Tangchun $\mathrm{Wu}, \mathrm{MD}$ and $\mathrm{PhD}$

Past President of the Cell Stress Society International (CSSI) and Senior Fellow Tangchun Wu has been elected to the Chinese Academy of Engineering, Division of Medicine and Health. Membership in the Chinese Academy of Engineering is considered the highest academic recognition in engineering science and technology in China. New members can only be elected by existing members to this lifelong honor. Only ten new members are elected every two years. Professor Tangchun $\mathrm{Wu}, \mathrm{MD}$ and $\mathrm{PhD}$, is a member of the Department of Occupational and Environmental Health. He is Director of the Key Laboratory of Environment and Health and the Ministry of Education and State Key Laboratory of Environmental Health (incubating). Professor Wu is Dean of the School of Public Health and Vice Dean of Tongji Medical College, Huazhong University of Science and Technology. He is a founding member of the CSSI and has published in and reviewed for many articles in Cell Stress and

Lawrence E. Hightower

lawrence.hightower@uconn.edu

1 Université Laval, Québec G1V 0A6, Canada

2 University of Connecticut, Storrs, CT, USA
Chaperones. Professor $\mathrm{Wu}$ is one of the most prolific authors in the twenty-six year history of our journal: articles listed in References (Xiao et al. 2002, 2003; Currie et al. 2004; Jin et al. 2004; Xu et al. 2004; Yang et al. 2004; Yuan et al. 2005; Zhou et al. 2005; Niu et al. 2006; Wu and Tanguay 2006; Yang et al. 2006; Tan et al. 2007; Yang et al. 2007; He et al. 2008; Wang et al. 2009; Zhang et al. 2010; Chen et al. 2012; Xin et al. 2012; Duan et al. 2014; Chen et al. 2015; Cui et al. 2015; Qian et al. 2016; Carra et al. 2019).

Tangchun Wu was the local organizer for two CSSI international workshops on the molecular biology of stress responses held in Wuhan, P.R. China in 1999 and 2004. The first of these international workshops was also the first formal event sponsored by the newly organized Cell Stress Society International. In 2015 Professor Wu along with Professor Lingjia Qian organized the Seventh International Congress on Stress Responses in Biology and Medicine held in Huangshan City, P.R. China. Throughout his career, Professor Wu has been a constant contributor to our society and our journal. We are delighted that he has been elected to the Chinese Academy of Engineering for his contributions to science.

\section{References}

Carra S et al (2019) Small heat shock proteins: multifaceted proteins with important implications for life. Cell Stress Chaperones 24(2):295-308

Chen $M$ et al (2012) Short (GT)nrepeats in heme oxygenase-1 gene promoter are associated with lower risk of coronary heart disease in subjects with high levels of oxidative stress. Cell Stress Chaperones 17(3):329-338

Chen W et al (2015) Response to: Hsp27 and Hsp70 in chronic obstructive pulmonary disease. Cell Stress Chaperones 20(5):725-726

Cui X et al (2015) COPD and levels of Hsp70 (HSPA1A) and Hsp27 (HSPB1) in plasma and lymphocytes among coal workers: a casecontrol study. Cell Stress Chaperones 20(3):473-481 
Currie RW et al (2004) Stress under the dam: meeting report of the Fourth International Workshop on the Molecular Biology of Stress Responses. Cell Stress Chaperones 9(3):221-228

Duan Y et al (2014) HspA1A facilitates DNA repair in human bronchial epithelial cells exposed to Benzo[a]pyrene and interacts with casein kinase 2. Cell Stress Chaperones 19(2):271-279

He M-A et al (2008) Genetic variation in heat shock protein 60 gene and coronary heart disease in China: tagging-SNP haplotype analysis in a case-control study. Cell Stress Chaperones 13(2):231-238

Jin X et al (2004) Serum and lymphocyte levels of heat shock protein 70 in aging: a study in the normal Chinese population. Cell Stress Chaperones 9(1):69-75

Niu P et al (2006) Overexpressed heat shock protein 70 protects cells against DNA damage caused by ultraviolet $\mathrm{C}$ in a dose-dependent manner. Cell Stress Chaperones 11(2):162-169

Qian L et al (2016) Stress and health Huangshan-style. Cell Stress Chaperones 21(3):373-378

Tan H et al (2007) Association of increased heat shock protein 70 levels in the lymphocyte with high risk of adverse pregnancy outcomes in early pregnancy: a nested case-control study. Cell Stress Chaperones 12(3):230-236

Wang F et al (2009) The level of Hsp27 in lymphocytes is negatively associated with a higher risk of lung cancer. Cell Stress Chaperones 14(3):245-251

Wu T, Tanguay RM (2006) Antibodies against heat shock proteins in environmental stresses and diseases: friend or foe? Cell Stress Chaperones 11(1):1-12

Xiao C et al (2002) Association of HSP70 and genotoxic damage in lymphocytes of workers exposed to coke-oven emission. Cell Stress Chaperones 7(4):396-402
Xiao C et al (2003) Basal and inducible levels of Hsp70 in patients with acute heat illness induced during training. Cell Stress Chaperones $8(1): 86-92$

Xin L et al (2012) Development of stable HSPA1A promoterdriven luciferase reporter HepG2 cells for assessing the toxicity of organic pollutants present in air. Cell Stress Chaperones 17(5):567-576

$\mathrm{Xu}$ YF et al (2004) Attenuation of okadaic acid-induced hyperphosphorylation of cytoskeletal proteins by heat preconditioning and its possible underlying mechanisms. Cell Stress Chaperones 9(3):304-312

Yang M et al (2004) Frequency-specific association of antibodies against heat shock proteins 60 and 70 with noise-induced hearing loss in Chinese workers. Cell Stress Chaperones 9(2):207-213

Yang M et al (2006) Association of hsp70 polymorphisms with risk of noise-induced hearing loss in Chinese automobile workers. Cell Stress Chaperones 11(3):233-239

Yang M et al (2007) Expression of heat shock proteins in myocardium of patients with atrial fibrillation. Cell Stress Chaperones 12(2): $142-150$

Yuan J et al (2005) Plasma antibodies to heat shock protein 60 and heat shock protein 70 are associated with increased risk of electrocardiograph abnormalities in automobile workers exposed to noise. Cell Stress Chaperones 10(2):126-135

Zhang X et al (2010) Plasma levels of Hsp70 and anti-Hsp70 antibody predict risk of acute coronary syndrome. Cell Stress Chaperones 15(5):675-686

Zhou F et al (2005) Association of hsp70-2 and hsp-hom gene polymorphisms with risk of acute high-altitude illness in a Chinese population. Cell Stress Chaperones 10(4):349-356

Publisher's note Springer Nature remains neutral with regard to jurisdictional claims in published maps and institutional affiliations. 